\title{
Historia@60: Reflecting and charting the landscape
}

Members of the editorial board weigh in on new directions in the historical discipline, the 21st century journal landscape and Historia's place therein.

\section{Goolam Vahed, University of KwaZulu-Natal}

The academic environment has changed dramatically in the past decade. Universities in South Africa, in common with many other parts of the world, have become highly corporatised and are now places of mass production of both teaching and scholarship which are seen as a means of revenue generation. Academics are compelled to achieve pre-set annual research outputs, and in order to meet these targets, they are sometimes forced to be less critical and theoretically less rigorous. Most of this work is published in academic journals. The problem is that four or five companies control the bulk of these journals. Even though they invest little in the research process, these companies charge exorbitant fees to access the journals, making it is impossible for academics and students in many parts of the world to engage with important publications in their respective fields. Each year, my own institution requests that we shed journals from the subscription list. Yet academics in the very countries that cannot afford to access certain journals are forced to publish in these "prestigious" and "high impact" publications to gain the academic standing that would allow them to apply for promotion, be invited to conferences, or even apply for research grants.

This trend needs to be resisted. Historia should remain a democratic voice, resist corporatisation, and continue to provide a means through which historians working on South Africa can publish their work. In keeping with the times, Historia should aim to provide Open Access online so that contributors' work can be easily accessed, read and debated to counter the monopoly of affluent institutions on the research agenda. Having critical and engaging work hidden in libraries serves little purpose. We are living in a political moment characterised by hyper-nationalist illiberal tendencies in which the teaching and writing of history is highly contested. In fact, many prefer to speak of "histories" rather than "history" because the past is always changing as we re-interpret it in light of the present. Historia should provide a forum for vigorous, jargon-free debate and complex interpretations on a broad field of issues - ranging, for example, from

\section{How to cite this article:}

G. Vahed, S. Sparks, L. van der Watt, G. Verbeeck, P. Limb, R. Williams and K. Horn, "From the editorial board. Historia@60: Reflecting and charting the landscape”, Historia 61, 1, May/Mei 2016, pp 11-16. http://dx.doi.org/10.17159/2309-8392/2016/v61n1a3

Copyright: (CThe Author(s). Published under a Creative Commons Attribution Licence. 
family life, to sport, the history of women, and the uses and abuses of memory - and ensure that this material is widely available.

\section{Stephen Sparks, University of Johannesburg}

In Northern scholarship the "transnational" turn, driven by primary source databases, continues apace. ${ }^{1}$ Our inability to access these databases and limited digitisation of sources here reinforces our parochialism. Northern scholarship will turn increasingly to exploring histories of migration, refugees and identity, to historicising the corrosion of contemporary democracies and the production of "new histories of capitalism". ${ }^{2}$ In South Africa we'll see further complexifying work on political struggle; a deepening of the "Bantustan turn"; further erosion of South African exceptionalism; more on consumption and the black middle class; new intellectual histories and more histories of science, technology and bureaucracy. Hopefully departments can make appointments which improve teaching conditions and provide opportunities for the generation of new black historians.

Journal databases are draining library budgets. Open source is much touted, though few prestigious journals are open source and journal costs must be covered by someone. Historia's Open Access status rests on free web-hosting and subsidisation by subscriptions and page fees, which depend on subsidies from government. How long is all of this sustainable?

"Publish or perish" represents a particular vulnerability for Historia. Rigorous editing and peer-reviewing will improve the quality of the journal. Peer reviewers and authors should be pushed to think, read and write more comparatively. I'd like to see more review essays, as well as more stock-taking via interviews with senior historians. Historia's ongoing transition from its rather insular, conservative past should be accelerated. This will require difficult decisions, including whether to join the Taylor \& Francis stable. This would increase Historia's exposure, secure its finances and facilitate increased quality of submissions. What about paywalls? There's always Sci-Hub. ${ }^{3}$

1. This kind of data-mining, methodology is not without its perils. See Lara Putnam "The Transnational and the Text-Searchable: Digitized Sources and the Shadows they Cast", The American Historical Review 121, 2 (2016), pp 377-402.

2. For an overview of this trend see Kenneth Lipartito, "Reassembling the Economic: New Departures in Historical Materialism", The American Historical Review 121, 1 (2016) pp 101-139.

3. https://sci-hub.io/ 


\section{Lize-Marié van der Watt, Umeå University}

Quality peer-reviewed, discipline-specific, accredited academic journals are still a mainstay of scholarly debate and production. It is not a perfect system, and HASA's Facebook page often posts debate articles on this. Nevertheless, for now it is the best we have them to promote intellectual vigour and critical thinking, especially in this information age. When academic publishing becomes monopolised by large for-profit cooperations, as is increasingly the case, publishing in and accessing journals becomes prohibitively expensive, especially for scholars working in developing countries. This, in combination with a "publish or perish" culture, then often drives scholars to predatory journals. Producing quality journals, distributing them widely and most of all making sure they are academically rigorous as well as interesting is, however, a costly affair. Historia is "green" Open Access (OA), thus available for self-archiving, and indexed on SciElO, an Open Access database developed in Brazil that specifically covers Latin America, the Caribbean and South Africa. The database has not been without its critics, 4 but it does provide a platform for scholarly visibility, which is crucial should any scholarly dialogue take place. Too often however, the inclusivity promoted by Open Access is taken to indicate non-selectiveness, a perception that is reinforced by the dubious quality of many OA journals. This does not have to be, and Historia should be careful not to compromise quality by remaining, and even increasing, selectivity, which could arguably make it a more attractive journal. Partly overlapping with the OA debate is the need for reaching wider audiences, outside our immediate discipline, and outside academia. Writing blog posts, for example, and communicating via social media, should not replace peer-reviewed articles - but learning how to do this well, and on credible platforms, will become increasingly important for academics of all disciplines. In an information-rich, knowledge-poor and highly contested public space, one of the greatest public services historians could provide is communicating two of the key tenets of our trade better: proper source criticism and an understanding of the power of narrative.

\section{Georgi Verbeeck, Maastricht University}

The landscape of academic journals is going through a process of hyper proliferation and specialisation. New journals on highly specialised topics are emerging, but also journals bridging the boundaries of established disciplines and methodologies. This reflects growing tendencies of professionalisation and compartmentalisation in academic research. It needs to be seen, however, whether this will not ultimately jeopardise the intellectual vitality of our academic community. Journals should invest more into intellectual debate and discussion, rather than the dissemination of highly fragmented knowledge. The historical sciences generally reflect these broader tendencies in

4. You can read the debate in the comments here: https://scholarlyoa.com/2015/07/30/isscielo-a-publication-favela/ 
academia. Historians should definitely approach their discipline as a socially and intellectually relevant enterprise. This should stimulate intellectual debate beyond the borders of its own discipline. History is well placed to cross the borders of the humanities and the social sciences. Its professionals should be welcomed to intervene directly in debates and discussions on issues that are directly relevant for people today. The studying of history is as old as the history of humanity and will most probably continue to play a key role in culture and society, albeit it in a different setting. Historia can play a pivotal role in putting history - its professionals, its practitioners, the interested readers and the general audience - into the centre of public discussion. May Historia serve as a meeting point for experts from various angles and origins with a shared interest in South African history.

\section{Peter Limb, Michigan State University}

Historia remains an important journal. It not only continues to publish wide-ranging and high-quality work but is also one of very few history journals still to publish in Afrikaans - and occasionally in African languages - unlike certain stubbornly Anglocentric journals. Another feature is its continuing commitment to reviewing an intellectually healthy variety of books, many not reviewed elsewhere. Reviews have declined in many journals, a trend due partly to the fact that companies now owning many of them have little incentive, because they sell articles at a higher premium (they will deny this but the numbers are persuasive). Historians do need reviews to keep abreast of the field, of changing trends and quality of published output. We cannot do this without reviews and it is to the great credit of Historia's dedicated past and present review editors that they have maintained this important feature for the profession.

Although on one level, the landscape of African journals has changed substantially over the last few decades, with many now online and possessing an online archive of back issues, on another level the form of content has remained largely the same: text articles, plus reviews and occasional features such as interviews. Yet, when the Internet was young, some of us dreamt of a "Journal of a New Kind" that would enable historians of South Africa fully to exploit online multimedia. A few journals have experimented with this, adding links to web addresses of oral interviews, and colour photographs, but in general, these dimensions remain underexploited. For African history, with its wealth of oral history, this should continue to be explored so readers could actually listen to, and see historical sources!

Historia should strive to maintain its independence as a scholarly association journal and maintain publishing in both English and Afrikaans, and if possible other languages. In terms of supplementing content with online features, it would be useful to allow the digital version to have hotlinks, particularly to oral interviews or other primary 
sources, so the journal can become more "alive"; possibilities of web interaction with readers might also be examined.

\section{Rosa Williams, University of the Free State}

The breaching of various kinds of boundaries seems likely to continue to impact the discipline of history and the place of journal publishing within it: the rise of the digital humanities has created new spaces and modes for professional historical scholarship to be disseminated; as other social sciences and humanities disciplines have survived their "historical turns", historians have been innovative and eclectic in repurposing methodologies and theories developed within these other disciplines; new historical subfields keep on emerging as existing ones crop up in "new" form (the "new imperial history", "new military history" and so on) and journals are launched to represent them. Historia must be attentive to these various forms of boundary-crossing as it seeks to represent the breadth of new scholarship on southern African history and historiography. But it is particularly well placed to engage with the present expansion in research on southern Africa that examines historical processes across national borders and draws connections and comparisons across regional, continental and global contexts. While the history of South Africa has dominated scholarship and publishing on the region as a whole, it is significant that the South African research community increasingly encompasses historians and historically-oriented scholars whose work is focused outside the country. By building on its existing links with this community and by forging stronger connections with research communities across the region, Historia is in a position to strengthen its role in providing an intellectual forum for research which unsettles the boundaries of South African and southern African history.

\section{Karen Horn, University of Stellenbosch}

In historical terms, a decade is a very short period indeed, but in terms of the knowledge era in which we find ourselves today, ten years is a very long time and there is no doubt that the historical discipline will have to adapt in order to remain relevant in an increasingly future-oriented world. Over the past few centuries, we have seen kings, emperors and dictators replaced by more egalitarian forms of government, while in other cases the opposite has taken place. As societies change, so historians reflect these changes in their work, not only with regard to the topics they select, but also in the way they present their work to their chosen audiences. More and more we will see historians looking to the past to investigate those aspects previous generations of scholars thought of as insignificant to society or of little worth to the discipline.

In essence, the next decade presents opportunities for new research methods into previously unexplored topics. Not only will historians cast their nets of enquiry wider, they will also use new media platforms to present their work to new audiences. 
Historians are now motivated by different circumstances than their predecessors, adapting their writing to different audiences as well as converging across different media types. In essence, the way history is written is changing because our reasons for writing history are changing. This will continue to happen, but at an ever increasing pace.

While some characteristics of history may change, the integrity of the discipline is not negotiable. The historian's ability to present an argument based on sound research, and to stand impartial amidst externally imposed and fleeting factors such as the politics of the day, are two aspects that come to mind. Another crucial attribute would be the historian's ability to conduct research of a high quality while the world demands research of a high quantity. 